\title{
A 2.45 GHz multicusp ECR-ion source for neutral-beam diagnostics at the tokamak TEXTOR
}

\author{
G. Mank, R. P. Schorn, and E. Hintz \\ Institut für Plasmaphysik, KFA Jülich, Ass. EURATOM-KFA, D-5170 Jülich, Germany \\ R. Papenbreer, H. M. Keller, D. Korzec, J. Bansky, and J. Engemann \\ BUGH Wuppertal, D-5600 Wuppertal, Germany
}

(Presented on 1 October 1991)

\begin{abstract}
In order to implement a new setup for neutral-beam activated impact excitation spectroscopy at the nuclear fusion experiment "TEXTOR" (Tokamak Experiment for Technology Oriented Research) a $2.45 \mathrm{GHz}$ ECR multicusp ion source was built. Special emphasis was given to extract an intense $\mathrm{He}^{+}$-ion beam, which will be used in the forthcoming experiment. After neutralization the slow $\left(2.2 \times 10^{7} \mathrm{~cm} / \mathrm{s}, 1 \mathrm{keV}\right) \mathrm{He}$ atoms are injected into the tokamak plasma. Necessarily the atom beam has to have a small divergence. To optimize the extraction optics, calculations concerning the multihole extraction aperture have been made, taking different ECR-plasma parameters into account. The divergence shows a strong dependence on the extracted beam current density $\left(>5 \mathrm{~mA} / \mathrm{cm}^{2}\right)$ and the chosen optics. The ion source has to be operated in a pulsed mode $(\max .5 \mathrm{kHz}$, duty cycle $50 \%$ ) due to experimental requirements.
\end{abstract}

\section{INTRODUCTION}

Neutral beams have been suggested and used ${ }^{1,2}$ as diagnostic tools for measurements concerning fusion plasma parameters. Especially neutral-beam-activated charge exchange spectroscopy proved to be an important tool in analyzing ion density distributions and temperatures. ${ }^{3}$ Neutral atom beams are also used to determine electron temperatures and densities in the plasma edge region of tokamaks. ${ }^{4}$ Recently, a thermal helium beam has been employed to determine the radial electron temperature distribution in the plasma boundary of the tokamak TEXTOR (Tokamak Experiment for Technology Oriented Research). ${ }^{5}$ Helium is an excellent candidate as an atomic probe because it has a high ionization energy and therefore can penetrate far into the tokamak plasma. First attempts to measure the electron temperature of a plasma using a helium beam have been made in the past, ${ }^{6-9}$ but were not satisfactory due to the lack of including multistep processes into the interpretation of spectroscopic data. Recently, a collisional radiative model has been developed ${ }^{10}$ that includes these processes and is capable of modeling the penetration and excitation of a slow helium beam passing through a plasma. The electron temperature in the plasma edge can be evaluated by comparing the intensity ratios of suitable chosen emission lines with the predictions of the model.

For the feasibility of these excitation measurements a He beam with a density of $2 \times 10^{7} \mathrm{~cm}^{-3}$ and a diameter of $40 \mathrm{~mm}$ has to be provided at the interaction region, resulting in an equivalent neutral current of $70 \mu \mathrm{A} / \mathrm{cm}^{2}$ at an energy of $1 \mathrm{keV}$. For this purpose a $\mathrm{He}$-ion beam has to be neutralized either in a He-gas or in alkali-metal vapors. In the latter case a considerable amount of metastable helium atoms will be produced. ${ }^{11}$

Electron cyclotron resonance (ECR) ion sources are capable of producing high beam current densities of inert and reactive gases. ${ }^{12-16}$ We have chosen to use an ECR ion source in our experiments because of the reliability and the stable conditions under which these sources can be operated.

In this report the operational characteristics of the source will be described with respect to the experimental necessities. Special regard will be given to the application of an ECR ion source used as a tool for plasma edge diagnostics. We will describe two types of multicusp ECR ion sources, one with a cylindrical resonator, the other with a rectangular resonator, which can both be operated in a pulsed high current mode. Calculations for the extraction show the difficulty in delivering high currents to the experimental region if only a two grid extraction optic is used. Finally, the experimental setup at TEXTOR will be briefly discussed.

\section{EXPERIMENTAL ARRANGEMENT}

For our purposes it seems to be adequate to use a compact multicusp ECR ion source. The cylindrical type of source (Fig. 1) that wc tested, is in many parts similar to other sources. ${ }^{12-16}$ The resonator was adjusted to a TE211 mode (diameter $=17 \mathrm{~cm}$, length $=8.5 \mathrm{~cm}$ ) by moving the sliding short to the appropriate position. The coaxial coupler could be slightly adjusted. The impedance of the ECR plasma is matched to the transmission line with a three stub tuner. The cylindrical plasma chamber consisted of a quartz tube with a length of $9 \mathrm{~cm}$ and an outer diameter of $7 \mathrm{~cm}$. The tube is sealed by an indium $O$ ring onto the stainless steel base plate. The quartz tube was surrounded by a 12-pole multicusp configuration consisting of rectangular NdFeB-permanent magnets $(1 \times 0.6 \times 3$ $\mathrm{cm})$. The remanence of these magnets is about $1100-1250$ $\mathrm{mT}$ and the Curie temperature is $310^{\circ} \mathrm{C}$. The gas inlet is integrated into the base plate. Different types of multigrid extraction optics can be mounted. The maximum active 


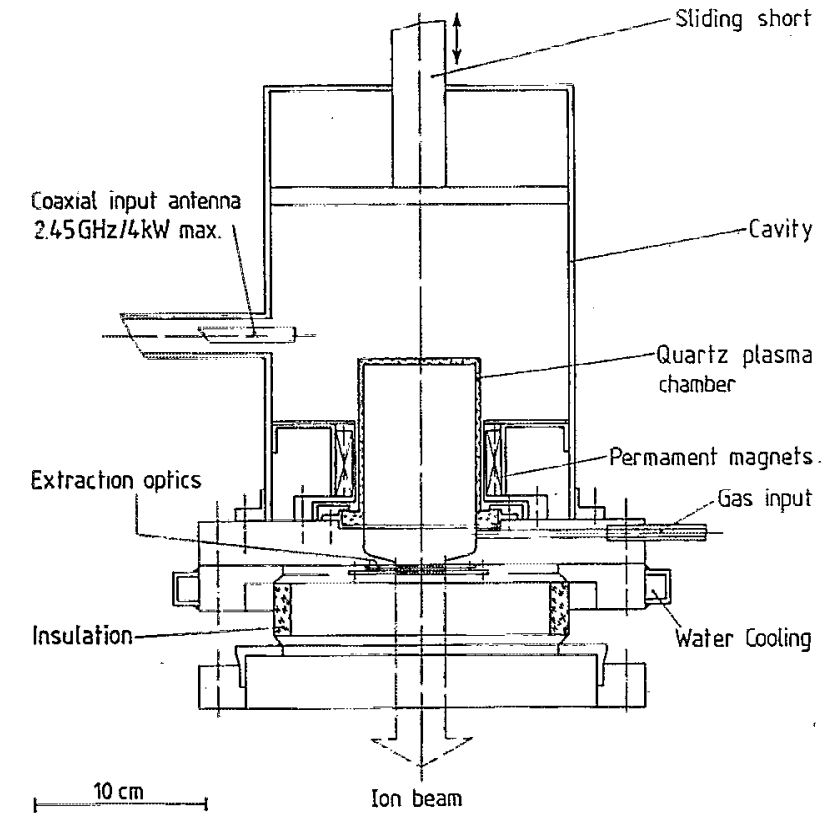

FIG. 1. Schematical drawing of the cylindrical ECR microwave-cavity source.

diameter of the extraction opening is $3 \mathrm{~cm}$. For test purposes we used two different types of grids: We employed a graphite grid optics, where we could adjust the distance of the two grids, and we used two-grid silicon optics. ${ }^{17}$ Water cooling was included into the high voltage insulator. No additional cooling of the extraction region was necessary. The source is designed for a maximum extraction voltage of $3 \mathrm{kV}$.

Operation is possible either in a cw mode or in a pulsed mode. Due to future experimental requirements we used the pulsed mode, and all tests concerning the operation of the sources were done by chopping the UHF transmitter with a rectangular pulse generator. The pulse frequency could be widely changed, but was mainly between $100 \mathrm{~Hz}$ and $5 \mathrm{kHz}$. In order to keep the heat load low, a duty cycle of $10 \%$ was chosen during the test period. Figure 2 shows the total extracted current for different gases. The ChildLangmuir limit could be reached for $\mathrm{Ar}, \mathrm{Ne}$, and $\mathrm{O}$, but for He the total extracted current was below this limit for an extraction voltage of $1250 \mathrm{~V}$. The UHF peak power was 4 $\mathrm{kW}$, showing a reflected power of about $10 \%$, which corresponds to a power density of more than $1 \mathrm{~W} / \mathrm{cm}^{3}$. The gas pressure, which could be measured only in the extraction region with a penning vacuum gauge, was about $2 \times 10^{-2} \mathrm{~Pa}$ for $\mathrm{Ar}, \mathrm{Ne}$, and $\mathrm{O}$ and about $6 \times 10^{-2} \mathrm{~Pa}$ for He.

We had the possibility to integrate different types of extraction optics into our setup. Due to experimental necessities we tried to include an extraction optics, which combines high output current densities and a low divergence. Different calculations were made, ${ }^{18}$ where our expected ECR-plasma parameters have been included. The calculations were done for an integrated green tape-silicon two-grid extraction optics, assuming oxygen as a working gas and an extraction voltage of $1000 \mathrm{~V}$. The silicon optics

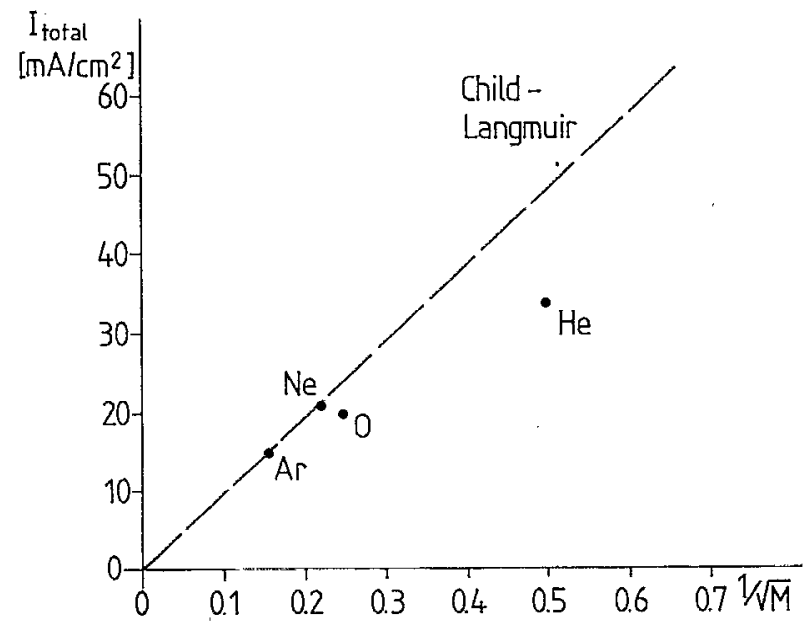

FIG. 2. Total extracted ion currents for different gases. Extraction voltage $1250 \mathrm{~V}$, extraction gap width $0.89 \mathrm{~mm}$, transparency of the silicon extraction optics $35 \%$.

are manufactured with rectangular holes of $0.85 \mathrm{~mm} \times 0.85$ $\mathrm{mm}$ and had a transmission of $35 \%$. The anisotropically etched silicon grids are bonded to a holder, which consists of DuPont Green Tape. ${ }^{\mathrm{TM}}$ Details can be found in Ref. 17. Figure 3 shows the results of the calculations using different ion saturation current densities as a parameter. The resulting ion current density $J_{-}$ion $\left(\mathrm{mA} / \mathrm{cm}^{2}\right) 1 \mathrm{~m}$ away from the point of extraction depends on the grid distance and the ion saturation current. Assuming an ion saturation current of $10-20 \mathrm{~mA} / \mathrm{cm}^{2}$, a grid distance of $1.2 \mathrm{~mm}$ seems to be the best choice. The divergence of the ion beam will
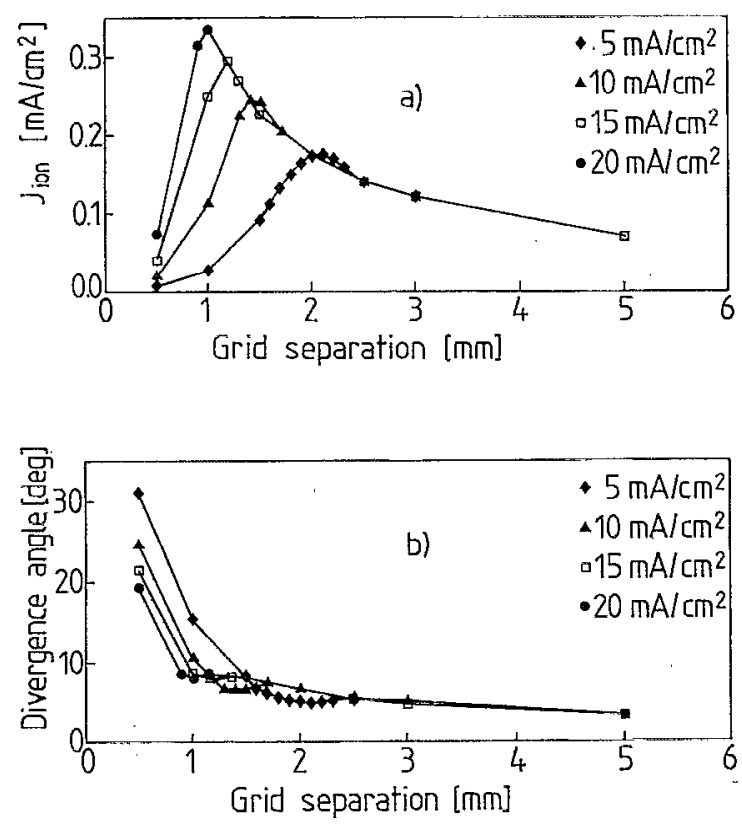

FIG. 3. Calculations of (a) the ion current density $J_{\text {ion }}\left(\mathrm{mA} / \mathrm{cm}^{2}\right) 1 \mathrm{~m}$ apart from the point of extraction and (b) the divergence angle for different grid separations and ion saturation currents $\left(\$ \mathrm{~mA} / \mathrm{cm}^{2}, \Delta: 10\right.$ $\mathrm{mA} / \mathrm{cm}^{2}, \square: 15 \mathrm{~mA} / \mathrm{cm}^{2}$, $\bullet: 20 \mathrm{~mA} / \mathrm{cm}^{2}$ ). The computations were performed for silicon optics with $1 \mathrm{~cm}$ diam. 


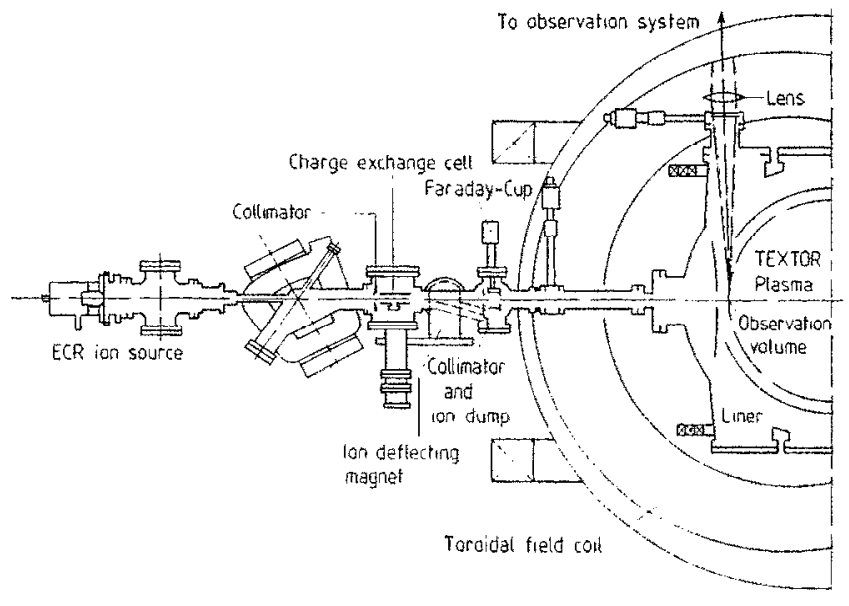

FIG. 4. The $2.45 \mathrm{GH}$. ECR ion source at the tokamak TEXTOR.

be less than $10^{\circ}$. As we expected higher saturation currents for $\mathrm{He}$, we have chosen a grid distance of $0.9 \mathrm{~mm}$. We measured a divergence of $8^{\circ} \pm 0.5^{\circ}$ for an oxygen beam, which is in good agreement with the calculations, and a divergence of about $9.5^{\circ} \pm 0.5^{\circ}$ for a $\mathrm{He}$ beam. The ion beams were not mass or energy analyzed. The divergence of the beam is directly dependent on the ECR-plasma parameters, which are changed by varying the gas pressure and the of power.

Although the cylindrical source worked very well during our test performances, the only drawback was the capacitive coupling of the waveguide to the resonator with a coaxial coupler. After a longer period of operation the temperature of the coupler changed and the UHF had to be retuned. Additionally we had $\mathrm{rf}$ leaks at this location. Therefore we decided to build an ECR source with a rectangular resonator and direct coupling of the waveguide to the resonator by using of a pyramidal horn antenna $\left(\Upsilon_{0}\right.$ $\left.=28.5^{\circ}, \vartheta_{0}=25^{\circ}\right)$. The resonator had a height of $6.1 \mathrm{~cm}$ and a volume of $1100 \mathrm{~cm}^{3}$. The resulting output was comparable to the cylindrical source output, but the gas pressure was lower $\left(4-5 \times 10^{-2} \mathrm{~Pa}\right.$ for $\left.\mathrm{He}\right)$ and the reflected power was higher (30\%). The ignition of the source was much easier to achieve and we had no rf leaks and nearly no heat load onto the coupling. As this source is easier to handle it seems appropriate to us to use this system for the planned experiments.

The ECR source will be included in an existing setup at TEXTOR ${ }^{4}$ (Fig. 4). The He-ion beam will be directed to a $\mathrm{Li}$-vapor neutralization cell ${ }^{19}$ through the gap of an analyzing magnet, which is used for another source. The non-neutralized beam fraction is deflected onto an ion dump, the current to which serves as a monitor signal for the injected atom beam. The He atom beam will be directed into the plasma of the tokamak. By measuring the intensities of two different spectral lines of $\mathrm{He}$, it should be possible to obtain the temperature of the electrons in the plasma using an impact excitation model. ${ }^{10}$ As the atom beam is chopped the background radiation can be subtracted from the recorded signals.

\section{CONCLUSION}

We have investigated two types of single-mode multicusp ECR ion sources. The cylindrical as well as the rectangular type are capable of delivering high total currents up to the Child-Langmuir limit. The UHF-power density is more than $1 \mathrm{~W} / \mathrm{cm}^{3}$. The drawback in operating these sources is the high divergence of the He-ion beam (about $10^{\circ}$ ) and the high pressure in the extraction region, the latter can be improved by better pumping, which will be included in the future. Investigations concerning the decrease of the beam divergence are in progress.

' H. Winter, Vacuum 37, 47 (1987).

${ }^{2}$ K. Kadota, K. Tsuchida, Y. Kawasumi, and J. Fujita, Plasma Phys. 20, 1011 (1978).

${ }^{3}$ R. P. Schorn, E. Hintz, D. Rusbüldt, F. Aumayr, M. Schneider, E. Unterreiter, and H. Winter, Appl. Phys. B 52, 71 (1991).

${ }^{4}$ A. Pospieszczyk, F. Aumayr, H. L. Bay, E. Hintz, P. Leismann, Y. T. Lie, G. G. Ross, D. Rusbüldt, R. P. Schorn, B. Schweer, and H. Winter, J. Nucl. Mat. 162-164, 574 (1989).

${ }^{5}$ B. Schweer, A. Pospieszczyk, G. Mank, U. Samm, B. Brosda, and B. Pohlmeyer, Eur. Phys. Conf. Abstr. 15C. IV-361 (1991).

${ }^{6} \mathrm{~S}$. P. Cunningham, Conference on Thermal Reactions (UCRL, Livermore, CA, 1955); U.S. Atomic Energy Commission Report No. 279, 289

${ }^{7}$ R. S. Sovie, Phys. Fluids 7, 613 (1964).

${ }^{8}$ B. J. Eastlund, D. Spero, M. Johnson, P. Korn, C. B. Wharton, and E. R. Wilson, J. Appl. Phys. 44, 4930 (1973).

${ }^{9}$ N. Brenning, J. Quant. Spectrose. Radiat. Transfer 24, 293 (1980).

${ }^{10} \mathrm{~B}$. Brosda and B. Pohlmeyer, Ruhr-Universität Bochum internal report, 1990.

${ }^{11}$ R. W. McCullough, T. V. Goffe, and H. B. Gilbody, J. Phys. B 11, 2333 (1978).

${ }^{12}$ J. Asmussen and M. Dahimene, J. Vac. Sci. Technol. B 5, 328 (1987).

${ }^{13}$ L. Mahoney, M. Dahimene, and J. Asmussen, Rev. Sci. Instrum. 59, 448 (1988).

${ }^{14}$ J. Hopwood. M. Dahimene, D. K. Reinhard, and J. Asmussen, J. Vac. Sci. Technol. B 6, 268 (1988).

${ }^{15} \mathrm{~J}$. Asmussen, J. Hopwond, and F. C. Sze, Rev. Sci. Instrum. 61, 250 (1990).

${ }^{16}$ L. Mahoney and J. Asmussen, Rev. Sci. Instrum. 61, 285 (1990).

${ }^{17} \mathrm{~J}$. Bansky, J. Engemann, H. M. Keller, and D. Korzec, these proceedings.

${ }^{18} \mathrm{D}$. Korzec and J. Engemann, these proceedings.

${ }^{19}$ K. MeCormick, Report IPP III/82, 1983, MPI für Plasmaphysik, Garching. 
Review of Scientific Instruments is copyrighted by the American Institute of Physics (AIP). Redistribution of journal material is subject to the AIP online journal license and/or AIP copyright. For more information, see http://ojps.aip.org/rsio/rsicr.jsp Copyright of Review of Scientific Instruments is the property of American Institute of Physics and its content may not be copied or emailed to multiple sites or posted to a listserv without the copyright holder's express written permission. However, users may print, download, or email articles for individual use. 